\title{
O autocuidado do psicólogo hospitalar frente à finitude de seus pacientes
}

\section{The hospital psychologist's self-care against of the patients finitude}

\author{
Fabian Graziele Nogueira de Oliveira ${ }^{1}$, Diego Saimon de Souza Abrantes $^{2}$ \\ 1 Acadêmica de Psicologia da Faculdade IMMES, Macapá, Amapá. https://orcid.org/0000-0003-2525-0359 E-mail: \\ grazielefabian2@gmail.com \\ 2 Psicólogo/coach, prof. Me. da Faculdade IMMES, Macapá, Amapá. http://orcid.org/0000-0003-0175-8342 E-mail: \\ diego_saimon@hotmail.com *autor para correspondência.
}

\author{
Palavras-chave \\ Morte \\ Psicologia hospitalar \\ Saúde mental \\ Resiliência \\ Psicoterapia
}

\begin{abstract}
o fazer do psicólogo hospitalar é permeado de desafios institucionais e emocionais, uma vez que relações são criadas nesse ambiente. Há psicólogos que precisam lidar com a morte de seus pacientes independente do contato estabelecido, sobretudo, enfrentar seus próprios sentimentos ocasionados pela morte do enfermo, além de encarar as familias desoladas pela perda. Pensando nisso, o objetivo deste estudo foi investigar maneiras das quais os psicólogos hospitalares podem adotar para trabalhar seu estado emocional e manter sua saúde mental sadia diante da morte de pacientes, mantendo o equilíbrio emocional para continuar com sua rotina. As descobertas foram endossadas pelo uso da técnica de análise de conteúdo, com tipologia bibliográfica. Foram utilizados os indexadores Pepsic, Scielo, Latindex e Biblioteca Virtual de Saúde como fontes de coleta das pesquisas. Isso se deu a partir das seguintes palavras-chave: psicólogo hospitalar; morte; pacientes internados; psicologia hospitalar; finitude; autoconhecimento; resiliência; psicoterapia; coaching; mentoring; yoga; meditação. Após o levantamento de dados, leitura flutuante e codificação, fez-se resumos. Os resultados revelaram que a graduação em psicologia é muitas vezes deficiente em preparar o aluno para lidar com a morte de pacientes, especialmente em ambientes hospitalares. Além disso, a realização da psicoterapia pessoal é de extrema relevância para se manter o estado emocional do psicólogo hospitalar em controle, pois ele pode e deve aprimorar as habilidades de resiliência e autocontrole. Práticas de relaxamento como a yoga e a meditação tem se mostrado ótimas alternativas de gerenciamento de estresse, sendo opções, portanto, para o exercício dessas habilidades. $O$ coaching, mentoring e a consultoria também auxiliam o profissional no processo de melhora emocional, permeando, mais uma vez, a resiliência e o autocontrole.
\end{abstract}

The hospital psychologist's work is permeated with institutional and emotional challenges, once relationships are created at the hospital environment. There are psychologists who need to deal with the death of their patients regardless of the contact established, withal, they have to face their own feelings by the death of the patient, also facing the families devastated by the loss. This study pretended to investigate ways in which hospital psychologists could adopt to work on their emotional state and keep their mental health healthy before the death of patients, maintaining emotional balance to continue with their routine. The study was endorsed by the use of content analysis technique, of bibliographic typology. Pepsic, Scielo, Latindex and Virtual Health Library indexes were used as sources of research collection. This happened from the following keywords: hospital psychologist; death; hospitalized patients; hospital psychology; finitude; self knowledge; resilience; psychotherapy; coaching; mentoring; yoga; meditation. After data collection, floating reading and coding, summaries were made. The results revealed that psychology gradutation is often lacking, not preparing the student to deal with the death of patients, especially in hospital environment. The performance of personal psychotherapy is extremely important to keep the emotional state of the hospital psychologist in control, as he can and must improve the skills of resilience and self-control. Relaxation practices, as yoga and meditation, had been shown excellent alternatives for stress management, seems to be options to exercise these skills. Coaching, mentoring and consulting also may help the professional in the process of emotional improvement, presenting, once again, the resilience and self-control.

\section{INTRODUÇÃO}

A atuação do psicólogo hospitalar está voltada a prevenção primária e secundária de saúde, bem como ao comprometimento social com outros profissionais em prol do bem-estar do paciente (CASTRO; BORNHOLDT, 2004).
Além de tentar minimizar o sofrimento psíquico do paciente acamado, da família dele e da equipe de saúde (ANGERAMICAMON et al, 2003; SIMONETTI, 2013). Este estudo é voltado especificamente ao psicólogo hospitalar que além de lidar com todas as exigências laborais, precisa encarar constantemente a finitude de seus pacientes. Daí a 
importância de se falar desse profissional que é munido de sentimentos e pode deixar de trabalhar seu estado emocional tornando seu trabalho, possivelmente, ineficiente.

Com a utilização da pesquisa bibliográfica, realizou-se buscas acerca da atuação do psicólogo hospitalar e a morte enquanto processo de finitude dos pacientes inseridos nesse contexto (GIL, 2014). Partindo desse pressuposto, o objetivo do estudo foi investigar maneiras que o psicólogo hospitalar pode adotar para trabalhar seu estado emocional diante do contexto mórbido do hospital, além de apresentar alternativas de gerenciamento de estresse, explanando o autoconhecimento e resiliência que podem ser aprimorados através de psicoterapia pessoal, participação de grupos terapêuticos, coaching, consultoria, mentoring, yoga e meditação.

Os resultados obtidos apontaram que a relação entre uma possível graduação deficiente, que não prepara o formando para lidar com temas ligados a morte, e a ausência da psicoterapia pessoal, podem tornar o trabalho do psicólogo hospitalar ineficiente ao lidar com a finitude de seus pacientes, uma vez que habilidades precisam ser adquiridas para a condução da profissão e o profissional talvez não as possua, como resiliência e autocontrole emocional. Descobriu-se que o autoconhecimento permite ao psicólogo determinar com mais precisão suas dificuldades e reconhecimento rápido dos momentos em que a morte de um paciente pode vir a afetar seu trabalho, reagindo velozmente para prevenção disso. Essa reação rápida é presente na habilidade denominada resiliência, tendo se percebido que dadas as características do contexto hospitalar, ela é de suma importância ao profissional da Psicologia que precisa ter autocontrole das emoções que sente frente ao ambiente de trabalho que o cerca.

\section{METODOLOGIA}

Tendo sido realizado no modelo de análise de conteúdo de Bardin (2016), este estudo priorizou o detalhamento dos dados e proporcionou aos investigadores uma visão geral e rigorosa de informações. Em relação ao delineamento, foi utilizada a pesquisa bibliográfica, pois esse método ofereceu um horizonte de possibilidades para se encontrar materiais já existentes sobre os objetos de estudo. Também se usou o método exploratório, em razão da pouca exploração do tema no meio cientifico (GIL, 2014).

A amostra da pesquisa contou com 47 materiais, dentre eles: livros, periódicos e artigos científicos. Os periódicos e artigos científicos deviam ser divulgados nas plataformas virtuais: Pepsic, Scielo, Latindex ou Biblioteca Virtual de Saúde (BVS), além de conter uma das seguintes palavras- chave: psicólogo hospitalar; morte; pacientes internados; psicologia hospitalar; finitude; autoconhecimento; resiliência; psicoterapia; coaching; mentoring; yoga; meditação. Essas escolhas se deram frente à necessidade de investigação dos elementos arguidos para comprovação ou refutação da hipótese de que o psicólogo precisa ter domínio de suas emoções, mesmo nos momentos mais tensos da morte de seus pacientes, para não ter seu trabalho prejudicado e acreditava-se na existência múltipla de caminhos que possibilitam o autocontrole do profissional da Psicologia.

Foram utilizados livros da autora Elisabeth Kübler-Ross, por ela ser pioneira em estudos de proximidade da morte com pacientes terminais. Também se destacou o uso de obras do autor Angerami-Camon, que possui vários livros sobre a temática de psicologia hospitalar em seus vários contextos, sendo considerado pesquisador clássico do tema. Ademais, obras de outros autores relacionadas a temática também foram levadas em consideração para enriquecimento da pesquisa, dada demonstração, em sinopse do livro, de conteúdo relevante para os objetivos deste estudo.

Não foram atribuídos períodos específicos de publicação a nenhuma das obras usadas em razão da necessária busca do tema, dada a relevância científica de objetos de estudo ligados a morte em hospitais e todos os materiais que não corresponderam aos critérios citados, foram excluídos da análise.

De modo procedural, para obtenção dos resultados, utilizou-se a análise de conteúdo de Bardin (2016), ou seja, desenvolveu-se três fases de pesquisa: a) pré-análise: selecionou-se os materiais bibliográficos por meio da leitura flutuante, da usabilidade para com os objetivos propostos e da criação de indicadores que facilitaram a interpretação final da análise, como: psicologia hospitalar; finitude ou morte de pacientes hospitalizados; metodologias de promoção ao autoconhecimento e autorreflexão; b) exploração do material: consistiu na tomada de decisões da pré-análise. Foram codificadas as mensagens, selecionaramse recortes das informações de acordo com a classificação estabelecida para análise e fez-se resumos desses referenciais; c) tratamento dos resultados obtidos e interpretação: condensaram-se as informações obtidas através dos resumos de modo a uni-las e depois interpretálas.

\section{Atuação do Psicólogo Hospitalar}

O exercício da profissão em psicologia hospitalar está voltado as condições que circundam o processo de doença, trabalhando-se com a prevenção primária e secundária no 
tratamento oferecido ao paciente, uma vez que medidas de educação do próprio sujeito podem favorecer a precaução do aparecimento ou agravamento da doença (CAMPOS, 1995). Em razão da preocupação biopsicossocial do psicólogo sobre seu paciente, a doença em si não passa a ser o foco das intervenções, mas a escuta terapêutica com usuários e familiares do sistema de saúde (FOSSI; GUARESCHI, 2004).

Logo, a conduta do psicólogo hospitalar se resume a orientação de apoio a familiares, equipe de saúde e doente diante da cruel realidade que permeia o contexto hospitalar. Desta forma, é indispensável que haja uma boa relação entre prática e teoria, no qual o profissional utiliza os recursos técnicos disponíveis que favorecem uma comunicação positiva em prol do bem-estar comum (SÁ et al, 2005). Angerami-Camon et al (1996) salientam que com a prática, os profissionais se interessam mais pelos aspectos emocionais da doença, o que torna o processo de adoecimento mais familiar ao psicólogo que lida constantemente com a morte de pacientes e seus familiares.

Segundo o Conselho Federal de Psicologia (CFP, 2007), o processo de adoecimento proporciona ao indivíduo a variabilidade psíquica voltada a promoção da saúde psicológica e biológica, emergindo a atuação do psicólogo hospitalar como um fator determinante no tratamento, tendo em vista a necessidade que cada demanda exige. Desta maneira, várias intervenções diferentes devem ser de domínio do psicólogo, como a utilização de grupos educativos que facilitem a compreensão da família e do paciente acerca do tratamento adequado e o trabalho em equipe multiprofissional que ofereçam uma relação favorável da família e paciente com os demais profissionais (ALMEIDA; MALAGRIS, 2011).

Para Angerami-Camon et al (2003, p. 23), "a psicologia hospitalar tem como objetivo principal a minimização do sofrimento provocado pela hospitalização". Desta forma, percebe-se que somente o fato de se estar dependente de familiares e profissionais da saúde causa desconforto ao paciente, uma vez que as suas escolhas não são levadas em consideração em razão da sua condição de acamado. O processo de hospitalização se configura em um ambiente desconfortável para o doente e a escolha de assistência psicológica deve se sobrepor a vontade do profissional, respeitando a autonomia e dignidade do sujeito. Desta maneira, o psicólogo deve agir cuidadosamente para não ser invasivo com o paciente, uma vez que a própria equipe de saúde ao efetuar seu trabalho, acaba por invadir o espaço do outro a partir de tantas intervenções médicas que precisam ser realizadas (ANGERAMI-CAMON et al, 2003).

Portanto, cabe a psicologia hospitalar elaborar não somente o trabalho individualizado voltado a dor do paciente, mas integrar também a angústia da família e o sofrimento disfarçado da equipe de saúde e médicos. Focase, sobretudo, na relação existente entre os fatores que compõe o funcionamento do processo hospitalar que são: paciente, família e médicos, buscando facilitar a interação entre as relações em função do conforto do paciente hospitalizado (SIMONETTI, 2013). Portanto, precisa-se reconhecer a perspicácia e controle emocional cobrado do psicólogo ao lidar com variados sofrimentos humanos inseridos no contexto hospitalar comumente entendido como estressante. Esse fator engloba a todos, afetando a ele próprio (ANGERAMI-CAMON et al, 2012).

\section{A morte no contexto hospitalar}

A morte é uma característica universal a todos os seres vivos, trazendo consigo sentidos singulares construídos a partir da história de vida do sujeito. No hospital, o doente, muitas vezes, não possui oportunidade de despedida dos entes queridos, sendo privado da presença de um rosto familiar próximo para afastar o sentimento de solidão. 0 medo da morte no contexto hospitalar é resultado da angústia em se estar sozinho e receios a uma experiência completamente nova permeada de sentimentos de angústia e dor (KOVÁCS, 1987; KÜBLER-ROSS, 1996). Percebe-se que o enfermo não possui escolhas diante de seu estado clínico, inferindo diretamente no estado emocional dos profissionais de saúde que estão presenciando a morte diariamente.

Em relação aos pacientes em estado terminal, KüblerRoss e Klessler (2004) salientam sobre a influência exercida do médico acerca das conclusões que o paciente terá sobre sua própria existência, sendo inconveniente forçar o paciente a aceitar sua morte, uma vez que depende somente do mesmo a elaboração desse luto que ocorre gradativamente. Desta forma, percebe-se que a aceitação da morte por parte do paciente e da própria equipe que compõe o hospital, é pouco discutida enquanto processo de finitude natural repleta de receios.

Angerami-Camon et al (2003) afirma que o conflito entre a morte e o viver afeta tanto o paciente quanto o próprio profissional de saúde que se depara com a finitude. Em relação ao psicólogo hospitalar nesse contexto, seus sentimentos podem ser afetados pela história de vida do acamado e a observação de todo o sofrimento da família, podendo interferir diretamente a qualidade de seu trabalho.

Nas Unidades de Terapia Intensiva (UTI) dos hospitais são encontrados diariamente médicos, enfermeiros, psicólogos e fisioterapeutas. Percebe-se a associação de suas atividades com a possível morte dos pacientes em estado grave (OLIVEIRA, 2002). O psicólogo, ali inserido, trabalha com a escuta especializada de familiares e lida factualmente com a 
morte no seu ambiente de trabalho, podendo abalar seu próprio estado emocional diante das difíceis demandas existentes (ANGERAMI-CAMON et al, 2003).

Portanto, na vida cotidiana dos psicólogos hospitalares, a morte está constantemente sendo pauta em conversas de corredores e enfermarias do hospital, sendo algo comum para esses trabalhadores, em uma sociedade em que há a crença inconsciente na imortalidade. Os profissionais de saúde são ensinados a cuidar da vida e não da morte, reforçando ainda mais o medo dela que o ser humano enfrenta (BRÊTAS; OLIVEIRA; YAMAGUTI, 2006; KÜBLERROSS, 2011).

\section{O psicólogo hospitalar diante a finitude dos pacientes}

Durante a graduação em Psicologia, o acadêmico, muitas vezes, não é direcionado em sua prática clínica a trabalhar com pacientes em estado terminal nos hospitais, o que dificulta seu contato direto com a finitude de seus pacientes. Segundo Silva e Ayres (2010), por ser uma temática de difícil discussão, muitos alunos concluem a graduação sem conhecer efetivamente o dinamismo da morte enquanto um fenômeno natural da sociedade. Ademais, desde a sua formação, o psicólogo não é preparado para as exigências do sistema de saúde, dentre elas, lidar com o falecimento das pessoas hospitalizadas (SEIDL; COSTA JÚNIOR, 1999).

Nesse contexto, além da graduação deficiente, o não investimento em psicoterapia pessoal influencia diretamente a conduta profissional do recém-formado, levando a possível dificuldade em lidar com a morte, demonstrando-se a necessidade de autoconhecimento para um trabalho mais eficiente. Para Faleiros (2004), o psicoterapeuta assume um papel intenso de agente de mudanças, uma vez que auxilia o outro na resolução de conflitos e angústias internas. Somase a isso, a importância da psicoterapia pessoal enquanto possibilidade de transformação individual e social do sujeito, tornando-o um profissional mais apto a lidar com a finitude de seus pacientes hospitalizados. Afinal, o psicólogo deve estar preparado a todo momento para a perda no hospital, em razão do contexto emergencial do ambiente e por manter contato direto com o paciente no acompanhamento de todas as etapas da doença (FREITAS; OLIVEIRA, 2010).

O profissional de saúde mental, no ambiente hospitalar, que não se permite demonstrar seu estado emocional frente a morte do paciente pode, consequentemente, apresentar problemas psicológicos de má elaboração do luto, em virtude da excessiva carga emocional de estresse que acompanha as demandas do hospital, não dando nem tempo para tal feito (KOVÁCS, 2005). A psicoterapia é um espaço para os profissionais elaborarem tais emoções, afinal os psicólogos são tão vulneráveis quanto o paciente que está acamado (ANGERAMI-CAMON et al, 2003). A psicoterapia de grupo também é um valioso recurso terapêutico de assistência a sua saúde mental (SOUZA et al, 2004; SILVA; COSTA, 2008). O psicólogo é munido de sentimentos e emoções que muitas vezes não podem ser expostas em determinado momento em respeito à sua própria conduta profissional.

Leite e Vila (2005) destacam que fatores estressores no ambiente de trabalho como sentimento de perda, dor ou sofrimento, podem tornar o local comprometido emocionalmente ocasionando problemas físicos ou psíquicos aos psicólogos. Problemas de saúde psicossomáticos que se referem a sintomas ou queixas físicas ligadas ao psíquico, podem ser ocasionados pelo ambiente de trabalho hospitalar, em razão do contato constante com o sofrimento do outro, relações interpessoais difíceis, inseguranças e medo de cometer erros (FREIRE, 2000; MOTA; MARTINS; VÉRAS, 2006). E diante desse cenário, é exigido do profissional a humanização do processo de hospitalização do paciente, quando o próprio psicólogo hospitalar, no exercício de sua profissão, está exposto a um contexto desumano (ANGERAMI-CAMON et al, 2012). Trindade et al (2014) afirmam que tudo isso tem a possibilidade de ocasionar pedidos de afastamentos por parte do trabalhador, munido de sentimentos de inferioridade.

O contato com as situações dos pacientes permite que o profissional volte seu olhar para sua própria vida, ressurgindo conflitos e frustrações por vezes deixadas de lado. Além disso, sem a resolução de seus próprios problemas internos, o profissional pode se tornar rígido nos atendimentos e se distanciar do outro como mecanismo de defesa que prejudica a si mesmo e ao seu trabalho (MOTA; MARTINS; VÉRAS, 2006).

\section{O autoconhecimento}

A relação entre o contexto hospitalar e autoconhecimento está pautada no descobrimento das limitações e potencialidades do psicólogo hospitalar, influenciando, sobretudo, os relacionamentos interpessoais estabelecidos pela equipe multiprofissional ou pelos familiares dos pacientes internados sob seus cuidados (HOGA, 2004).

Branden (1998) enaltece que o autoconhecimento tem forte potencial de influência na autoestima das pessoas. Para o autor, ambos os conceitos estão voltados a capacidade do sujeito em lidar com as adversidades do cotidiano, destacando que a autoestima influi a competência pessoal que diz respeito a autoconfiança, relacionada a capacidade de resolução de conflitos.

Trabalhar o autoconhecimento em prol da melhora da 
autoestima do psicólogo demonstra-se essencial, uma vez que este lida diretamente com as questões emocionais dos indivíduos hospitalizados e com suas patologias, vendo-os serem curados ou falecendo por isso (FALEIROS, 2004; FREITAS; OLIVEIRA, 2010). Hoga (2004) aponta ainda a importância do autoconhecimento para que o psicólogo consiga separar seus sentimentos e emoções do que estiver sendo apresentado pelos pacientes hospitalizados, não prejudicando o tratamento deles e nem seu trabalho.

Segundo Freud (1910 apud LAPLANCHE; PONTALIS, 2001), o autoconhecimento é importante para que o psicólogo não interfira, inconscientemente, na relação terapêutica com a contra-transferência, pois é nesse momento em que psicólogo pode misturar suas emoções com a fala e sofrimento do paciente, atrapalhando seu trabalho com possíveis condutas antiprofissionais.

Hoga (2004) afirma que a contra-transferência pode interferir no atendimento sem que o psicólogo tome consciência, por exemplo, se o psicólogo hospitalar não gostar de determinada característica do doente, este pode, inconscientemente, rejeitar o atendimento do paciente, não o tratando adequadamente. Daí a importância do autoconhecimento que por vezes só pode ser alcançado com a ajuda da psicoterapia pessoal. Laplanche e Pontalis (2001) recomendam que a psicoterapia pessoal do psicólogo ocorra concomitante ao atendimento de seus pacientes, uma vez que a autoanálise permitirá ao profissional conhecer suas próprias capacidades e resistências interiores frente as demandas trazidas pelo paciente, no caso do hospital, pacientes acamados, que comem, banham-se e dormem nesse local.

Além da importância da psicoterapia pessoal para alcançar o autoconhecimento, há também o coaching, mentoring e a consultoria. Segundo Lopez (2016), o coaching refere-se a um processo de ferramentas que auxiliam o coachee (pessoa que procura ajuda) a compreender suas capacidades e deficiências pessoais ou profissionais que podem interferir no desempenho de metas e ações. E isso é proporcionado justamente através da promoção ao autoconhecimento. Todo processo de coaching gera o autoconhecimento (SARGES; ABRANTES, 2019).

Belo e Accioly (2015) concordam com o processo de coaching e acrescentam que o sistema organizacional, no caso deste estudo, o hospital, deve oferecer um modelo de gestão mentoring, que possibilite o crescimento e avanço individual do profissional, no qual o indivíduo possa desenvolver e aprimorar competências através de mentores que auxiliem no processo pessoal e, consequentemente, profissional do sujeito. Associado ao coaching e mentoring, Block (2001) salienta também a importância da consultoria que busca ajudar o cliente a compreender melhor seu funcionamento e se tornar agente de mudanças, atitude que depende somente do próprio sujeito.

Essas são alternativas de trabalhos que tem o compromisso de promover o autoconhecimento. Pensando no psicólogo hospitalar, cria-se a expectativa que, através delas, ele se torne um profissional ainda mais focado, eficiente e com maior autocontrole de suas emoções frente à rotina potencialmente estressora do hospital, tendo que lidar, ainda, com as situações em que seus pacientes, alguns que ele acompanha há meses, morrem. Diante desse cenário, o psicólogo hospitalar precisa manter o autocontrole e capacidade de resiliência frente as demandas que surgem e para isso é importante a prática de algumas das alternativas mostradas anteriormente.

\section{A resiliência}

Sinônimo de invulnerabilidade aos fenômenos, resiliência compreende os mecanismos de enfrentamento da realidade, no qual é possível se aprimorar as capacidades e habilidades pessoais, estando diretamente relacionada a maneira como se estabelecem as relações interpessoais (ASSIS; PESCE; AVANCI, 2006; BRANDÃO; MAHFOUD; GIANORDOLINASCIMENTO, 2011). Yunes (2003) usa a expressão "superação" para designar uma pessoa em processo de resiliência. Essa capacidade individual, faz com que o sujeito perceba como as suas próprias atitudes beneficiam sua vida, conseguindo identificar acontecimentos estressantes ou perturbadores capazes de alterar seus planos e metas (RUDNICKI, 2007).

Yunes (2003), Moraes e Rabinovich (1996) afirmam que a partir da habilidade de resiliência, é possível se enfrentar as adversidades do cotidiano através de uma combinação de fatores como influências ambientais e psicológicas que moldam a vida do indivíduo. Rudnicki (2007) salienta a importância da resiliência ao psicólogo hospitalar devido aos já discutidos fatores estressantes e mórbidos que acompanham o fazer psicológico diariamente. Para o autor, pessoas resilientes enfrentam eventos estressores de maneira adequada e conseguem manter seu equilíbrio pessoal estável no ambiente de trabalho, não experimentando sintomas disfuncionais que possam interferir na sua atividade profissional.

Indivíduos resilientes conseguem resolver conflitos facilmente, pois o sujeito possui habilidades de autoconhecimento que o conduzem a descobrir maneiras de obtenção do controle das situações, o que contribui bastante no ambiente de trabalho, neste caso, o hospital (TEIXEIRA; SANTANA, 2015). Diante disso, o psicólogo hospitalar que lida diariamente com a finitude de pacientes, precisa manter esse autocontrole emocional que pode ser alcançado através 
de psicoterapia pessoal, grupal, coaching, mentoring e consultoria, como citado anteriormente.

Além dessas práticas, há também outras alternativas de gerenciamento de estresse e melhora do estado de saúde, além da formação ou melhoria da habilidade de resiliência, que são a yoga e meditação. Elas referem-se a formas de medicina alternativa, no qual uma única sessão de posturas de yoga e meditação mostram efeitos significativos no contexto psicológico e fisiológico do sujeito (MELVILLE et al, 2012), interferindo diretamente no âmbito laboral do profissional praticante, neste caso, o psicólogo hospitalar, que com essas práticas pode se tornar mais resiliente junto ao aprendizado do autocontrole, propagado pela via do autoconhecimento físico e emocional. Só a meditação, por exemplo, tem poder para propagar intensas melhorias na saúde mental dos sujeitos que, conscientemente, se submetem ao processo, visto que a prática relaxa o corpo em seu sentido orgânico e psíquico (MENEZES; DELL'AGLIO, 2009; ASSIS, 2013). Freud (2010) explica que a meditação pode neutralizar os instintos, pacificando as insatisfações e provocando mais sensações de prazer.

A yoga refere-se a um recurso terapêutico gerador de autoconhecimento que estimula hábitos saudáveis, além de amenizar patologias ou sintomas no sujeito. Por outro lado, a meditação funciona como auxílio na prevenção de várias doenças psicossomáticas como o estresse e ansiedade, bem como promove a sensação de bem-estar através da manutenção da saúde mental (MENEZES; DELL'AGLIO, 2009; VORKAPIC; RANGÉ, 2011; BARROS et al, 2014). A partir dessas duas práticas terapêuticas úteis, é possível se gerenciar o estado emocional do profissional praticante, além de fortalecer a capacidade de resiliência, especialmente do psicólogo hospitalar, que precisa recorrer a essa habilidade constantemente, para enfrentar as difíceis demandas e, especificamente, lidar com a finitude daqueles que ele acompanha e se importa, seus pacientes.

\section{CONSIDERAÇÕES FINAIS}

A morte é uma temática de difícil discussão na sociedade contemporânea por causar receios acerca de um fenômeno que transpira receio. E no contexto hospitalar, o psicólogo constantemente é solicitado para amenizar e ouvir o sofrimento de familiares de pacientes que faleceram ou manter contato direto com pacientes terminais que repentinamente podem morrer. Daí a importância de se falar no estado mental do psicólogo hospitalar, visto que lidar com os aspectos emocionais do outro pode causar exaustão emocional, doenças psicossomáticas e problemas interpessoais que interferem na efetividade do trabalho do profissional, ainda mais quando esse contato está no limiar das emoções daqueles que lidam com a morte no dia-a-dia.

Diante disso, foi possível evidenciar a necessidade de um preparo mais adequado por parte dos acadêmicos de psicologia, que por vezes não tem contato com o fenômeno da morte no contexto hospitalar, por isso muitos profissionais sentem um impacto ao enfrentar as demandas exigidas pelo local quando graduados. Além do mais, a realização da psicoterapia pessoal desde a graduação é de extrema importância para que nos atendimentos, o psicólogo hospitalar seja capaz de identificar suas próprias capacidades e resistências interiores frente a finitude de pacientes.

Deste modo, os objetivos do estudo foram alcançados bem como a hipótese foi comprovada, uma vez que a psicoterapia pessoal, terapia de grupo, coaching, mentoring, consultoria, yoga e meditação podem proporcionar ao psicólogo hospitalar o autoconhecimento e a resiliência, dois conceitos de extrema importância para a condução do fazer psicológico frente a finitude de pacientes, o que relativamente condiz com os propósitos iniciais da análise.

Através da pesquisa bibliográfica adotada, pôde-se perceber a escassez de publicações científicas entrelaçando as variáveis deste estudo, em específico. Por isso, propõe-se que mais pesquisas sejam realizadas com ênfase na saúde mental do psicólogo hospitalar que lida constantemente com a finitude dos pacientes, pois no contexto hospitalar tem-se a necessidade de cuidar somente do paciente, e o profissional acaba por não cuidar de seu próprio estado emocional frente as exigências do ambiente de trabalho.

\section{REFERÊNCIAS}

ALMEIDA, R. A.; MALAGRIS, L. E. N. A prática da psicologia da saúde. Rev. SBPH, Rio de Janeiro, v. 14, p. 183-202, 2011. Disponível em: <http://pepsic.bvsalud.org/scielo.php?script=sci_arttext \&pid=S151608582011000200012\&lng=pt\&nrm=iso $>$. Acesso em: 20 mar. 2020.

ANGERAMI-CAMON, V. A. et al. E a psicologia entrou no hospital. São Paulo: Cengage Learning, 1996.

Psicologia hospitalar: Teoria e Prática. São Paulo: Pioneira Thomson Learning, 2003.

Psicossomática e suas interfases: o processo silencioso do adoecimento. São Paulo: Cengage Learning, 2012.

ASSIS, D. A. Os benefícios da meditação: melhora na qualidade de vida, no controle do stress e no alcance de metas. Revista Interesp., n. 3, 2013. Disponível em: <https://revistas.pucsp.br/index.php/interespe/article/vi 
ewFile/17445/12968>. Acesso em: 25 abr. 2020.

ASSIS, S. G.; PESCE, R. P.; AVANCl, J. Q. Resiliência: enfatizando a proteção dos adolescentes. Porto Alegre: Artmed, 2006.

BARDIN, L. Análise de conteúdo. São Paulo: Edições 70, 2016.

BARROS, N. F. et al. Yoga e promoção da saúde. Ciência e saúde coletiva, v. 19, n. 4, Rio de Janeiro, p. 1305-1314, 2014.

Disponível

em:<http://www.scielo.br/scielo.php?script=sci_arttext\& pid=S141381232014000401305\&lng=en\&nrm=iso $>$.

Acesso em: 16 abr. 2020.

BELO, A. C. C.; ACCIOLY, S. A mentoria como influência de pessoas no ambiente organizacional. Cadernos de Graduação - Ciências humanas e sociais, v. 3, n.1, Maceió, p. 185-200, 2015. Disponível em: <https://periodicos.set.edu.br/index.php/fitshumanas/ar ticle/view/1967/1517>. Acesso em: 10 abr. 2020.

BLOCK, P. Consultoria: o desafio da liberdade. 2. ed. São Paulo: Pearson Makron Books, 2001.

BRANDÃO, J. M.; MAHFOUD, M.; GIANORDOLINASCIMENTO, I. F. A construção do conceito de resiliência em psicologia: discutindo as origens. Paidéia, Ribeirão Preto, v. 21, p. 263-271, 2011. Disponível em: <http://www.scielo.br/scielo.php?script=sci_artext\&pid= S0103-863X2011000200014\&lng=en\&nrm=iso>. Acesso em: 12 abr. 2020.

BRANDEN, N. Auto-estima: como aprender a gostar de si mesmo. 18. ed. São Paulo: Saraiva, 1998.

BRÊTAS, J. R. S.; OLIVEIRA, J. R.; YAMAGUTI, L. Reflexões de estudantes de enfermagem sobre morte e o morrer. Rev. esc. enferm. USP, São Paulo, v. 40, n. 4, p. $477-$ 483, 2006.

CAMPOS, T.C. P. Psicologia hospitalar: a atuação do psicólogo em hospitais. São Paulo: Pedagógica e Universitária Ltda, 1995.

CASTRO, E. K.; BORNHOLDT, E. Psicologia da saúde $x$ psicologia hospitalar: definições e possibilidades de inserção profissional. Psicologia, ciência e profissão, Brasília, v. 24, n. 3, p. 48-57, 2004. Disponível em <http://pepsic.bvsalud.org/scielo.php?script=sci_arttext \&pid=S141498932004000300007\&lng=pt\&nrm=iso>. Acesso em: 23 abr. 2020.

CFP. Resolução n. 013, de 01 de junho de 2007. Institui a Consolidação das Resoluções relativas ao Título Profissional de Especialista em Psicologia e dispõe sobre normas e procedimentos para seu registro. Disponível em: $<$ https://site.cfp.org.br/wpcontent/uploads/2008/08/Resolucao_CFP_ nx_0 132007.pdf>. Acesso em: 20 mar. 2020.
FALEIROS, E. A. Aprendendo a ser psicoterapeuta. Psicologia, ciência e profissão, Brasília, v. 24, n. 1, p.14-27, 2004. Disponível em: $<$ http://pepsic.bvsalud.org/scielo.php?script=sci_arttext \&pid=S141498932004000100003\&lng=pt\&nrm=iso>. Acesso em: 20 mar. 2020.

FOSSI, L. B.; GUARESCHI, N. M. F. A psicologia hospitalar e as equipes multidisciplinares. Rev. SBPH, Rio de Janeiro, v. 7, n. 1, p. 29-43, 2004. Disponível em: $<$ http://pepsic.bvsalud.org/scielo.php?script=sci_arttext \&pid=S151608582004000100004\&lng=pt\&nrm=iso $>$.

Acesso em: 20 mar. 2020.

FREIRE, C. A. O corpo reflete o seu drama: somatodrama como abordagem psicossomática. São Paulo: Ágora, 2000.

FREITAS, A. F. S. C.; OLIVEIRA, S. A. Os impactos emocionais sofridos pelo profissional de psicologia frente à morte em contexto hospitalar. Akrópolis Umuarama, v. 18, n. 4, p. 263-273, 2010. Disponível em: <https://revistas.unipar.br/index.php/akropolis/article/vi ew/3297/2277> Acesso em: 23 mar. 2020.

FREUD, S. O mal-estar na civilização e outros textos, novas conferências introdutórias e outros textos (1930-1936). Rio de Janeiro: Cia das Letras, 2010.

GIL, A. C. Métodos e técnicas de pesquisa social. 6. ed. São Paulo: Atlas S. A., 2014.

HOGA, L. A. K. A dimensão subjetiva do profissional na humanização da assistência à saúde: uma reflexão. Revista da escola de enfermagem da USP, v. 38, n. 1, São Paulo, p. 13-20, 2004. Disponível em: $<$ http://www.scielo.br/scielo.php?script=sci_arttext\&pid $=$ =\$0080-62342004000100002\&lng=en\&nrm=iso>. Acesso em: 09 abr. 2020.

KOVÁCS, M. J. O medo da morte, uma abordagem multidimensional. Boletim de psicologia, São Paulo, p. 58-62, $1987 . \quad$ Disponível em: <https://pesquisa.bvsalud.org/portal/resource/pt/lil54972>. Acesso em: 19 mar. 2020.

Educação para a morte. Psicologia, ciência e profissão, Brasília, v. 25, n. 3, p. 484-497, $2005 . \quad$ Disponível em: <http://www.scielo.br/scielo.php?script=sci_arttext\&pid $=$ S1414-98932005000300012\&Ing=en\&nrm=iso $>$. Acesso em: 20 mar. 2020.

KÜBLER-ROSS, E. A roda da vida: memórias do viver e do morrer. 2. ed., Rio de Janeiro: Sextante, 2011.

Sobre a morte e o morrer: o que os doentes têm para ensinar os médicos, enfermeiras, religiosos e aos seus próprios parentes. 7. ed., São Paulo: Martins Fontes, 1996.

KÜBLER-ROSS, E.; KLESSLER, D. Os segredos da vida. 4. ed., 
Rio de Janeiro: Sextante, 2004.

LAPLANCHE, J.; PONTALIS, J.B. Vocabulário da psicanálise. 4. ed., São Paulo: Martins Fontes, 2001.

LEITE, M. A.; VILA, V. S. C. Dificuldades vivenciadas pela equipe multiprofissional na unidade de terapia intensiva. Rev. Latino-Am. enfermagem, Ribeirão Preto, v. 13 , n. 2, p. 145-150, 2005. Disponível em: <http://www.scielo.br/scielo.php?script=sci_arttext\&pid $=$ S0104-11692005000200003\&lng=en\&nrm=isso $>$.

Acesso em: 30 mar. 2020.

LOPEZ, V. A. Coaching: modismo ou uma ferramenta de gestão de pessoas que veio para ficar?, Rio Grande do Sul, 2016. Disponível em: <http://www2.al.rs.gov.br/Biblioteca/LinkClick.aspx?fileti cket=abmhFsTPojE\%3D\&tabid=5639>. Acesso em: 09 abr. 2020.

MELVILLE G. W. et al. Quinze minutos de posturas de ioga com base em cadeiras ou meditação guiada executada no escritório podem provocar uma resposta de relaxamento. Medicina alternativa e complementar baseada em evidências, 2012. Disponível em: <https://www.hindawi.com/journals/ecam/2012/501986 />. Acesso em: 13 abr. 2020.

MENEZES, C. B.; DELL'AGLIO, D. D. Os efeitos da meditação à luz da investigação científica em Psicologia: revisão de literatura. Psicologia, ciência e profissão, Brasília, v. 29, n. 2, p. 276-289, 2009. Disponível em: $<$ http://pepsic.bvsalud.org/scielo.Php?script=sci_arttext \&pid=S1414-98932009000200006\&lng=pt\&nrm=isso $>$. Acesso em: 14 abr. 2020.

MORAES, M. C. L.; RABINOVICH, E. P. Resiliência: Uma Discussão introdutória. Rev. Bras. Cresc. Desenv. Hum., São Paulo, 1996. Disponível em: <http://www.revistas.usp.br/jhgd/article/view/38369>. Acesso em: 14 abr. 2020.

MOTA, R. A.; MARTINS, C. G. M.; VÉRAS, R. M. Papel dos profissionais de saúde na política de humanização hospitalar. Psicologia em estudo, Maringá, v. 11, n. 2, p. 323-330, $2006 . \quad$ Disponível em: <http://www.scielo.br/pdf/pe/v11n2/v11n2a10.pdf>. Acesso em: 30 mar. 2020.

OLIVEIRA, E. C. N. O psicólogo na UTI: reflexões sobre a saúde, vida e morte nossa de cada dia. Psicol. cienc. prof., Brasília, v. 22, n. 2, p. 30-41, 2002. Disponível em: <http://www.scielo.br/scielo.php?script=sci_arttext\&pid $=$ S1414-98932002000200005\&lng=en\&nrm=iso>. Acesso em: 23 mar. 2020.

RUDNICKI, T. Resiliência e o trabalho do psicólogo hospitalar: considerações iniciais. Rev. SBPH, Rio de Janeiro, v. 10, n. 2, p. 83-92, $2007 . \quad$ Disponível em <http://pepsic.bvsalud.org/scielo.php?script=sci_arttext
\&pid=S1516-08582007000200010\&lng=pt\&nrm=iso >. Acesso em: 14 abr. 2020.

SÁ, A. K. J. M et al. Psicólogo hospitalar da cidade de Recife PE formação e atuação. Psicologia, ciência e profissão, Brasília, vol.25, n.3, 2005. Disponível em: <http://pepsic.bvsalud.org/scielo.php?script=sci_arttext \&pid=S1414-98932005000300005\&lng=pt\&nrm=iso>. Acesso em: 20 mar. 2020

SARGES; C. M.; ABRANTES, D. S. S. A. O processo de coaching na liderança organizacional. Anal de evento XIII Semana Acadêmica IMMES - Regionalizando a ciência com valor social, 24 de outubro de 2019.

SEIDL, E. M. F.; COSTA JÚNIOR, A. L. O psicólogo na rede pública de saúde do Distrito Federal. Psicologia: Teoria e Pesquisa, Brasília, vol. 15, n. 1, p. 27-35, 1999. Disponível em: <revistaptp.unb.br>. Acesso em: 15 mar. 2020.

SILVA, G. S. N.; AYRES, J. R. C. M. O encontro com a morte: à procura do mestre Quíron na formação médica. Rev. bras. educ. med., Rio de Janeiro, v. 34, n. 4, p. 487496, 2010. Disponível em: $<$ http://www.scielo.br/scielo.php?script=sci_arttext\&pid =S0100-55022010000400003\&lng=en\&nrm=iso> Acesso em: 25 mar. 2020.

SILVA, E. A.; COSTA, I. I. Saúde mental dos trabalhadores em saúde mental: estudo exploratório com os profissionais dos Centros de Atenção Psicossocial de Goiânia/Go. Psicologia em revista, Belo Horizonte, v. 14, n. 1, p. 83106, 2008. Disponível em: <http://pepsic.bvsalud.org/scielo.php?script=sci_arttext \&pid=S1677-11682008000100006\&lng=pt\&nrm=isso >. Acesso em: 30 mar. 2020.

SIMONETTI, A. Manual de psicologia hospitalar: o mapa da doença. 7. ed., São Paulo: Casa do psicólogo, 2013.

SOUZA, A. M. A. et al. Grupo terapêutico: sistematização da assistência de enfermagem em saúde mental. Texto e contexto - enfermagem, Florianópolis, v. 13, n. 4, p. 625632, $2004 . \quad$ Disponível em: <http://www.scielo.br/scielo.php?script=sci_arttext\&pid =S0104-07072004000400016\&lng=en\&nrm=iso>. Acesso em: 30 mar. 2020.

TEIXEIRA, L. F. L.; SANTANA, L. C. Um olhar sobre a resiliência na visão de gestores e colaboradores. Revista de iniciação científica, Cairu, v. 02, p. 14-32, 2015. Disponível em: <https://www.cairu.br/riccairu/pdf/artigos/1/2_OLHAR_ RESILIENCIA_VISAO_GEST_COLAB.pdf>. Acesso em: 12 mar. 2020.

TRINDADE, L. L. et al. Absenteísmo na equipe da doença e não no ambiente hospitalar. Enfermagem global, Múrcia, p. $2014 . \quad$ Disponível em: http://scielo.isciii.es/pdf/eg/v13n36/docencia3.pdf 
<http://scielo.isciii.es/pdf/eg/v13n36/docencia3.pdf>. Acesso em: 30 mar. 2020.

VORKAPIC, C. F.; RANGÉ, B. Os benefícios da Yoga nos transtornos de ansiedade. Revista brasileira de terapias cognitivas, Rio de Janeiro, vol. 1, n.7, p. 50-54, 2011. Disponível em:

<http://pepsic.bvsalud.org/scielo.php?script=sci_arttext \&pid=S1808-56872011000100009\&lng=pt\&nrm=iso $>$. Acesso em: 29 abr. 2020.

YUNES, M. A. M. Psicologia positiva e resiliência: o foco no indivíduo e na família. Psicologia em estudo, Maringá, v. 8, p. 75-84, 2003. Disponível em: <https://www.scielo.br/pdf/pe/v8nspe/v8nesa10.pdf>. Acesso em: 01 mai. 2020.

Submissão: 25/05/2020

Aprovado para publicação: 31/07/2020 